\title{
Reform on the Training Methods for Practical Undergraduate Talents from the Perspective of Maker
}

\author{
Minglei Jiang \\ Neusoft Institut \\ Foshan, Guangdong, China
}

\begin{abstract}
Thinking of the value of Maker Education from the perspective of Maker, the successor of craftsman spirit, we can find the training methods of practical undergraduate talents have similarities with the methods of Maker Education. In reference of the Maker Education, the paper seeks for the way of reform of practical undergraduate talents training methods so as to make the practical undergraduate education become the creative and innovative education.
\end{abstract}

Keywords—maker; craftsman spirit; talent training

\section{INTRODUCTION}

With the rapid development of internet and cross-board electronic commerce since the new century, the original diversification of mass market has been greatly released and the internet also opens the door to the public and provides the service of manufacturing as needed based on the internet. The special-interest products which can meet the various consumer market segment demands are put on the virtual goods shelves, therefore, anyone can sell any innovative products to anyone else. The rapid development of convenient manufacturing technologies and the information technology including the open source hardware, open source software and social networking services reduces the threshold for transferring ideas into prototype products for the grass roots, therefore, they can accomplish the research, development and creation processes of traditional elite enterprises or the individual monopoly with low costs and the Maker rises at this moment.

\section{CONCEPT OF MAKER}

Although the academia has not given the acknowledged definition of the Maker, it is not hard to find that the Maker is a group of people loving or enjoying innovation and also a kind of culture, a kind of attitude and a kind of learning style.

The Maker is a group of creative designers and implementers with strong intrinsic motivation and driven by interests. Although with the tortuous creative process, suffering of various challenges, difficulties and setbacks, they still can hold the life attitudes of omnipotence and not following common ways.

The Maker is the social culture of freedom, open and democracy which is propagated by the grass roots. It can build

The article is the phased result of "Reform and Practice for the Artistic Designing Specialized Courses of Practical Undergraduate based on the Theory of Maker" of the reform project for the higher education in 2015 issued by the Department of Education of Guangdong Province, Y. J. G. H (2015) No. 173 the social culture with no restrains, free play and open communication which all people can participate in to encourage more people who love creation, exploration and sharing to create the unique products and services through designing, manufacturing, modifying and perfecting in person. The Maker is a kind of research and experiential learning style with manual operation. Creation is learning. The creation of a piece of works usually needs to cross several subjects and comprehensively applies multiple kinds of knowledge and skills and needs continuous exploration, experience, test and check.

The Maker can continuously learn new knowledge during the problems solving process and internalize, consolidate and promote the knowledge through practical application. This kind of personalized manual exploration ability and problem solving ability are exactly what have been ignored and are urgently needed to be enhanced by current school education. The Maker Education also provides new solving ideas to solve the practical problems like high scores and low abilities and shortage of innovative talents etc existing in the current talent training.

\section{THE MAKER IS THE SUCCESSOR OF CRAFTSMAN SPIRITS}

What is embodied on the Makers is the spirit of continuous pursuing innovation which is not about sex and not about whether materialized products can be created, but just about the attitudes towards working. This kind of attitude can be traced with the same origin with the craftsman spirits.

The ancient Chinese craftsman spirits is derived from the Mohist School with the special "notable doctrine" characteristics. The creator of Mohist School, Mo Di possessed the craftsman background and his followers also came from "agriculture and worker". The Mohist School was an important school in the Warring States Period and was also the important origin of the thoughts of "law", "interest" and "skills". Thereafter, the various schools made brilliant achievements in the fields of epistemology and logic etc. Taoist School also had its comprehension of craftsman spirits. In "the skill can be enhanced to be close to arts and the arts can be enhanced to be close to the nature", Zhuangzi gave his understanding of the three states of "law", "art" and "nature" which can be deemed as the high-level research for the craftsman spirits of Chinese. 
With the establishment of the stratified modem enterprise system in modern times, the refinement of social division of labor and the prevalence of mechanized large-scale production, craftsman gradually disappeared on the full automatic production lines so that many people are worrying that the craftsman sprits will die out. However, the coming of Maker activities breaks this worry and the Maker spirits become the successor of craftsman spirits in the information era. Benefiting from the empowerment of new industrial revolution, the carriers of this spirits become the grass roots instead of elites. As the evolution of craftsman spirits, the Maker spirits also possess certain new features to adapt to the society. There are three aspects of those features. From the perspective of personal growth, the Maker spirits advocate the individual selfimprovement, pursuing and emancipation of characteristics; from the perspective of social development, the Maker spirits advocate cooperative sharing and integrated innovation; from the perspective of national prosperity, the Maker spirits advocate to practice and tools-orientation and civil wisdom as well as strong state. As the integration, the three constitutes the essence of the Maker spirits, that are, the spiritual connotations of Zonetry Culture.

Therefore, regardless of the individual, society or the nationality and country, the cultivation of the Zonetry Culture with the Maker spirits has become the necessary choice. The research and practice of Maker Education has also become the historic task in the new period of human education when facing the learner individuals, society, nationality and country.

\section{VALUE OF THE MAKer EdUCATION}

The Maker Education is a kind of integrated information technology which is the new educational mode bearing the educational concept of "open, innovation, exploration and experience and taking "creating Chinese learning" as main learning style and taking the training of various innovative talents as the purpose. The traditional education possesses profound industrialized sear making it the typical KnowledgeBased Education; while the Maker Education is the Competence-Based Education which can adapt to the era of knowledge economy and take the competence as the orientation.

Actually, we can understand the Maker Education from two perspectives: one is the "Maker's Education" which aims at the training of Maker's talents; the other kind is the "Education of Maker type" which aims at reforming education by the application of Maker theories and modes. For the "Maker's Education", it can carried out by setting up special Maker courses and establishing the Maker space as well as equipping with professional teachers; for the "Education of Maker type" it needs to blend the idea of "manual operation, practice and experience" in the teaching process of various subjects advocated by the Maker activities and launch the knowledge-based learning.

Whether it is the "Maker's Education" or the "Education of Maker type", the final educational purposes are the same, that is to train the innovative talents with innovative consciousness, competence and thoughts. Therefore, the two are mutually integrated and can mutually support each other. The launch of
Education of Maker type will certainly make more students to possess the Maker thoughts and Maker competence and then become the real Makers; the setting up of special Maker courses and the training of Maker talents will promote creation-based learning in other subjects for students.

\section{A. Concept}

Launch "Maker Education" and take the "creation-based learning" as the learning style that students actually need. "Creation-based learning" points to train the innovative interest, confidence and competence of students which should be the main idea of school educational objectives. The creation in technology era blends in with the methods and resources of various subjects such as engineering science, design science and computer science etc.

The development of science and technology provides students with more and more new tools, new materials and new techniques, which make it possible that every student may become the actual Maker and provides all students with appropriate environment, resources and opportunities for the creation. Especially, upon the technical tools and resources, students can blend the learning process in the creating process to realize the creation-based learning; can improve the subject learning quality during the creating process, especially can promote the confidence, creativity and interest in the learning of subjects such as science, technology, engineering, math and arts etc (Maker Education Initiative); can be immersed in the process of creation-based learning and train their critical thinking, innovative thinking and problem-solving ability so as to realize the whole-person development. Creation, technology and whole-person development are the most center three key words in the connotations of Maker Education.

\section{B. Value}

The Maker Education possesses infinite potency of value which can exert great influence on the individual development, course reform, education system reform and the national talent strategy.

The first is the individual development level. The Maker Education can better release the nature of learners and give them more space and opportunities of manual operation, free exploration and development. Through the "Maker Activities", students can know more the newest technologies and bring their creative ideas into reality upon the technologies and continuously motivate their interests for creation. Through the cooperation and exchange, thinking collisions and mutual help, more original thoughts can be produced and the campus culture of loving creation, enjoying creation and respecting creation can be formed and the creativity, practical ability, problem-solving ability as well as the team-work ability of students can be further promoted. In addition, the process of exploration of students is also the process of knowledge application process which is helpful to enhance the understanding of abstract subject knowledge. The Maker Learning can exert great active promotion on the cognitive development of students such as promotion of the student selfefficacy and enhancing learning motivation etc. 
The second is the course reform level. The course reform should lead the social development instead of passive pursuing and adapting. The Maker Education provides new "thoughts" and "route" for the launch of the theory of new course. The various creation-based learning styles such as manual operation, collaborative exploration and program cooperation and continuous Maker courses establishment and launch are helpful to completely solve the various real problems such as obsolete course contents, inflexible course structure, disjointed with the society, unitary teaching method and so on so as to drive the effective reform of the whole course system.

The third is the education system reform level. The organization and launch of Maker Education will further promote the optimization grouping and transformation and upgrading of key elements of education system (course system, teaching methods, technique environment, evaluation mechanism and teaching staff etc). Under the promotion of Maker Education, all the social power and resources such as school, family, community and enterprises etc will be fully mobilized to synergistically build the ubiquitous Maker Space, seamlessly connect the formal education and informal education and finally reconstruct the entire ecology of education and realize the real innovative education.

The fourth is the national talent strategy level. In the era of knowledge economy, the innovative talents are the strategic resources of national development and the essential condition to construct the innovative country. To implement the Planning Framework on National Medium and Long Term Talent Development (2010-2020), our country is actively organizing and implementing the innovative talents promotion plans to cultivate various types of high-level innovative scientific talents. The Maker Education is created for "innovation". In the recent hundreds of years, lack of innovation has always been the dilemma faced by our country. The Maker Education will promote the accelerating transition of national talents cultivation mode (from standardization to individuation, from singularization to diversification) and cultivate large quantities of "practical" scientific innovative talents and provide talent support for the construction of innovative country.

\section{REFERENCE OF THE TRAINING METHOd OF PRACTICAL UNDERGRADUATE TALENTS}

The Maker Education endows the students with more rights of freedom and options to let them follow their hearts and unhurriedly select the creative subjects, materials, tools and partners etc and design, manufacture, check and enjoy the fan of creation by person. The Maker Education also can restore the "fan" of learning and liberate the nature. The interest is the best teacher and the core power to motivate and maintain the human creativity. The educators should provide all the environments beneficial to creation for students and provide timely instruction and encourages. The Maker Education always points at the solving of real problems and let the students find the real problems and seek for the creative solutions and make it real through efforts. The problem solving is not like the examination which is the process for seeking for specific answer in the single subject and single knowledge point, while the problem solving rooted in the real conditions needs to comprehensively apply knowledge of multiple subjects and keep the optimistic mentality at the same time and the creative solutions may be produced through persistent efforts. The Maker Education advocates to viewing the Maker Activities as carrier to break the subject limit and cultivate the innovative talents with practical ability and innovative spirits through cross-subject and transboundary cooperative research. Therefore, the Maker Education has practical significance to the training of practical undergraduate talents and is worthy of reference and learning.

\section{A. Reform of Educational Concept}

The true learning is not just the process of obtaining information through classes, more importantly, is to learn through practice in the complicated social realities. The habitual education mode which takes subject knowledge as core and takes reasoning and infusion as main methods emphasizes on the master of concepts, judgment and principles but ignores the psychological process of individual feelings, experiences, comprehension and imagination etc. The isolated and still subject theory learning usually will result in that students pay more attention on the memorizing of abstract graphical representations and principles but ignore to understand the relations between the learnt knowledge and complicated and ever-changing social realities. The practical undergraduate education advocates "make Chinese knowledge" and even the "creation of Chinese knowledge" to let students coordinate to find and analyze problems, find solutions, create the project works and accomplish the process of "let those using mind use labor and let those using labor use mind, use both hands and minds" in the real creative and innovative programs. Because the creative process blends in the different knowledge and skills of multiple subjects, during the creative process, students can realize the experience, internalization and consolidation of knowledge and skills and finally realize "mental creation" and "master of both hands and minds".

\section{B. Reform of Course System and Contents}

The reconstruction of course system and stepping into the creative, innovative and practical courses can apply the Maker Theory to reform the course contents and structures which is the important tendency of new course reform development. To better implement the practical undergraduate education, we need to further optimize the current course system: firstly, emphasis on the integration of multiple subject contents and the contemporaneity of course materials, that is, the connection between learnt contents and the development of era should be more close; secondly, emphasis on the integration of information technology. Any subjects can introduce various technical tools, software platform and media materials etc and promote the information literacy of students along with the promotion of subject teaching; thirdly, emphasis on the practicalness of subject activities and ensure the students to operate. And the organization of textbook contents, exercises and supplementary teaching materials should be led by the activities instead of the didactic or practice-type organization modes. According to the needs of subject teaching, combining with the subject contents, reasonably set practical and Makertype subjects to meet the needs of course teaching. 
A good application-type and Maker-type issue shall include eight elements: correlation (be related with the actual situation of students), ample time (provide enough the time in class and after class), complexity (involving many subject knowledge), high-involvement (attract students to highly involve in for a long time), relatedness (students cooperate and interact and contact external specialists), availability (at all times access and use any materials, tools, software and hardware, etc.), sharing (share everything with others), and novelty (not repeat existing research)

Creative-type, innovation-type, and application-type thinking mode belong to growth-type, that is, when facing difficulties and setbacks the strategy and thinking for solving problems can be flexibly changed and surroundings and conditions are made use of efficiently. Application-type undergraduate course is not a course but a series of subject combination from lower level to advanced level. The introductory courses can focus on the teaching and operation skill training on fundamental subject knowledge; intermediate courses can focus on relatively complicated skill training; for advanced courses, conduct comprehensive innovative actual combat, centering on a certain reality project and problem, let students commonly create new plans and products through forming a team.

\section{Revolution of Requirements for Teachers}

Creative type, innovation type and application type courses require that application-type undergraduate courses need a professional teacher team with comprehensive quality, creativity and innovation consciousness.

Qualified application-type teachers for undergraduates shall have some core qualities:

(1) Super strong learning ability: be capable of quickly entering a certain field of subject.

(2) Solid application ability for information technology: deftly master the application and operation of different kinds of hardware and software technologies, equipment, tools and materials.

(3) Achieve mastery through a comprehensive study of the subject and know innovation and application.

(4) Be tireless in teaching, and have enlightening and inductive teaching ability, and reasonably inspire and guide students to create without telling them answers.

(5) Have a broad interpersonal circle, and make friends with experts outside schools, engineers and peer teachers, and with the help from them better guide students to create.

For The roles of application-type teachers for undergraduates from teachers to coaches, the reconstruction of the role of teachers and tasks can be divided into four types:

At first, teachers are the Designer of learning circumstance who shall design and solve the learning projects for actual problems in life for learners.

Moreover, teachers are the Manager of people resources who are in charge of the allocation of people in the project group and the mutual cooperation between learners with different cognition level, learning preferences, and ability direction, and meanwhile allocation various kinds of resources for different projects such as learning resources of projects that need skills, processing equipment for big-size and small-size electric appliances, open source hardware and kinds of auxiliary equipment for development.

Next, teachers are the Coordinator of students' learning process, and when projects start, teachers provide suitable task scaffolding for students to let students timely remove the scaffolding during autonomous practice.

At last, teachers are also the improver of practice quality who play the function of quality monitoring during projectbased learning of students and at any time master the rate of progress for different learning groups and the running situation for people cooperation and division of labor, and when difficulties appear in tasks, teachers provide suitable technical guidance and the persuasion of psychological states to let students from beginning to end in an active learning state. Application-type teachers for undergraduates are like the role of coaches and not like the initiators of book knowledge.

\section{CONCLUSION}

\section{A. Cognition}

Maker education refers to "whole-person development" centering on creative development and is a direction that is worthy of being explored for training program for applicationtype talents with bachelor's degree.

At first, creation-based study refers to the whole learning for whole-man development. Whole-man study includes six basic elements, of which the first element is subject knowledge, that is, learners can effectively construct and apply content knowledge, and develop the factual knowledge and conceptual knowledge into advanced knowledge in rule form to realize the transformation from declarative knowledge to procedural knowledge; the second element is innovation and creation, that is, through tests, practice and creation learners consider failure as the new opportunity to advance growth in order to generate new originalities and solutions to problems; the third element is self-cognition, that is, learners can awake to the needs in aspects of affective development, physical stamina development, and knowledge and skills learning, adjust themselves flexibly so as to maintain rich learning motivation and the best learning state and finally promote self-growth; the fourth element is cooperation, that is, learners can share knowledge \& resources, diversified arguments and experience with others to commonly realize the group goals and form active and interdependent cooperative relations; the fifth element is effective communication, that is, through different ways, learners effectively expound their understandings, and actively listen to and understand listeners, and establish connection; the sixth element is sense of responsibility, that is, learners can be responsible for their action, understand their influence, and cultivate the enthusiasm for assuming the responsibility and take active actions. Through analyzing the six elements for whole learning, the whole-man development under the circumstances of creation education not only embodies the accumulation of knowledge and the development 
of practice-based innovation ability but also contains the cultivation of students' self-cognition ability, the development of cooperation ability, the enhancement of communicative ability and the cultivation of sense of responsibility.

In the meantime, the Maker education focuses on the cultivation of students' creativity, and creation is often regarded as the topic related with "intelligence", but in essence, though the level of creativity of human is relevant to "intelligence", it is not completely determined by intelligence. Creativity is a comprehensive ability including many nonintellectual factors such as the interest, motivation, emotion and will of human. For example, under the field of vision of educational psychology, people with strong creativity generally have five-aspect behaviors: keep an optimistic and humorous state of mind when facing problems that are solved difficultly; remains be willing to find the fun and value in monotonous problem situations or objects that are considered no value by others; be more persistent when encountering with difficulty; be easier or be accustomed to finding problems in complex circumstances; compared with ordinary people in daily life have more dreams. It shows that the generation and development of creativity emphasized by Maker education not only needs the active participation of students' intelligence and also needs the input of students' emotion and the persistence of will, which is an important embodiment of whole-man development.

\section{B. Thinking}

1) How to break through the traditional course barrier: Differentiated subject classification easily leads to the thinking rigidity of learners, and learners often cannot step over the hedges between subjects to realize the fusion of knowledge and skills of different subjects in order to systematically solve problems. The programs in Maker education often need to invoke knowledge and skills of different subjects, so for the teaching mode for traditional one-fold subjects, regardless of information technology education, physics, or mathematics all cannot meet the requirements of Maker education all alone, so the nature of fused subjects needs to be explored urgently.

2) How to obtain the qualified application-orientation and innovation-type teachers: After the application-type undergraduate education spreads on a national scale, the fusion of many subjects will bring most of teachers for traditional subjects a huge challenge.

Aiming at the problem, it's necessary to deliberate over and establish an integrative teacher training system for application-type and innovation-type teachers before and after service.

3) How to evaluate the performance for application-type and innovation-type education: Traditional test-based result evaluation method is able to measure the degree of acquisition for system knowledge of learners but cannot measure the enhancement of learners' solving ability for innovation problems and the degree of contribution of individual in groups, so regardless of the enhancement of students' ability themselves or the evaluation of overall implementation efficiency of application-type undergraduate education, which all needs to explore performance evaluation mechanism integrating result-based evaluation and process-based evaluation method.

4) How to establish theory for Maker education: As a kind of new educational form, only establish its own theory system can application-type education obtain long-term development. The theory system involves many fields such as theory basis, teaching model \&mode, development path and model for teacher profession, construction of learning environment, resource construction and application system, and education performance assessment.

\section{REFERENCES}

[1] Luo Bing China Maker 3.0: In the future 5 years China will enter the era of "National Maker" [N] Science and Technology Daily, April 23, 2015 (the 8 th edition)

[2] Zhu Zhiting, and Sun Yanyan Maker Education: Practice field for innovation education of information technology- enabled[J] China Educational Technology, 2015,(1): 14-21

[3] Li Siqu, and Shao Peiren 2012: Development report for China entertainment and creative industry [M]. Hangzhou: Periodical office for China Media Report, 2012.

[4] Xiang Yong and Quan Jiyong: Korean Country-founding Research for culture industry[J] Journal of Huazhong Normal University(humanistic and social edition), 2013, (4): 107-112

[5] Chen Lin and Chen Yaohua (2013): Path analysis of informatization promoting educational modernization [J]. Educational Research (11): 114-118

[6] Huang Dongzhu and Yuewei (2011): Humanology question of innovative educational practice[J] Journal of The Chinese Society of Education (12):21-23,30

[7] Li Ling and Wang Jie (2014)"Maker" Change education softly [N].China Education Daily, September 23, 2014 (005)

[8] Liang Jian (2011) Some reflections on innovative education and educational innovation [J] Studies In Foreign Education, (10):12-15

[9] Wang Yunbiao (2014) Motivation and cultivation of innovative courage in teacher education [J] Journal of Higher Education , (8): 77 81 